\title{
FRACTIONAL INTEGRAL OPERATORS ON CENTRAL MORREY SPACES
}

\section{YASUO KOMORI-FURUYA AND ENJI SATO}

Abstract. We consider the boudedness of fractional integral operators on localized (central) Morrey spaces and investigate the relation between the Adams inequality and the Spanne inequality.

Mathematics subject classification (2010): 42B20, 42B25.

Keywords and phrases: The Adams inequality, Morrey space, central Morrey space, fractional integral operator, radial function.

\section{REFERENCES}

[1] D. R. AdAMS, A note on Riesz potentials, Duke Math. J. 42 (1979), 765-778.

[2] J. Alvarez, J. Lakey and M. Guzman-Partida, Spaces of bounded $\lambda$-central mean oscillation, Morrey spaces, and $\lambda$-central Carleson measures, Collect. Math. 51, 1 (2000), 1-47.

[3] V. I. Burenkov, A. Gogatishvili, V. S. Guliyev and R. Ch. Mustafayev, Boundedness of the Riesz potential in local Morrey-type spaces, Potential Anal. 35, 1 (2011), 67-87.

[4] J. DuOANDIKOETXEA, Fractional integrals on radial functions with applications to weighted inequalities, Ann. Mat. Pura Appl. 192, 4 (2013), 553-568.

[5] Z. W. FU, Y. LIN, AND S. Z. LU, $\lambda$-central BMO estimates for commutators of singular integral operators with rough kernels, Acta Math. Sin., Engl. Ser. 24, 3 (2008), 373-386.

[6] J. L. García-Cuerva And M.-J. Herrero, A theory of Hardy spaces associated to the Herz spaces, Proc. Lond. Math. Soc. III. Ser. 69, 3 (1994), 605-628.

[7] A. Gogatishvili and R. Ch. Mustafayev, New pre-dual space of Morrey spaces, J. Math. Anal. Appl. 397, 2 (2013), 678-692.

[8] A. Gogatishvili And R. Ch. Mustafayev, A note on boundedness of the Hardy-Littlewood maximal operator on Morrey spaces, Mediterr. J. Math. 13, 4 (2016), 1885-1891.

[9] L. I. HedBerg, On certain convolution inequalities, Proc. Am. Math. Soc. 36 (1972), 505-510.

[10] C. B. Morrey JR., On the solutions of quasi-linear elliptic partial differential equations, Trans. Am. Math. Soc. 43 (1938), 126-166.

[11] P. De Nápoli, I. Drelichman and R. G. Durán, On weighted inequalities for fractional integrals of radial functions, Ill. J. Math. 55, 2 (2011), 575-587.

[12] J. PeEtre, On the theory of $\mathscr{L}_{p, \lambda}$ spaces, J. Funct. Anal. 4 (1969), 71-87. 